Article

\title{
Enhancement of Thermal Diffusivity in Phase-Separated Bismaleimide/Poly(ether imide) Composite Films Containing Needle-Shaped ZnO Particles
}

\author{
Shoya Uchida, Ryohei Ishige and Shinji Ando* \\ Department of Chemistry and Material Engineering, Tokyo Institute of Technology, Ookayama, Meguro-ku, \\ Tokyo 152-8552, Japan; excellented@hotmail.co.jp (S.U.); rishige@polymer.titech.ac.jp (R.I.) \\ * Correspondence: sando@polymer.titech.ac.jp; Tel.: +81-3-5734-2137; Fax: +81-3-5734-2889 \\ Academic Editor: Sheng-Huei Hsiao \\ Received: 27 May 2017; Accepted: 27 June 2017; Published: 2 July 2017
}

\begin{abstract}
Phase-separated polymer blend composite films exhibiting high thermal diffusivity were prepared by blending a soluble polyimide (BPADA-MPD) and a bismaleimide (BMI) with needle-shaped zinc oxide (n-ZnO) particles followed by high-temperature curing at $250{ }^{\circ} \mathrm{C}$. Images recorded with a field-emission scanning electron microscope (FE-SEM) equipped with wavelength-dispersive spectroscopy (WDS) demonstrated that the spontaneously separated phases in the composite films were aligned along the out-of-plane direction, and the $\mathrm{n}-\mathrm{ZnO}$ particles were selectively incorporated into the BMI phase. The out-of-plane thermal diffusivity of the composite films was significantly higher than those of the previously reported composite films at lower filler contents. Based on wide-angle X-ray diffraction (WAXD) patterns and image analysis, the enhanced thermal diffusivity was attributed to the confinement of the anisotropically shaped particles and their nearly isotropic orientation in one phase of the composite films.
\end{abstract}

Keywords: polymer blend; thermal diffusivity; soluble polyimide; bismaleimide; needle-shaped zinc oxide

\section{Introduction}

The minimization and advanced performance of state-of-the-art electronic devices urgently require improvements in heat dissipation from electronic components loaded on flexible printed circuit boards. Since heat is transported along the out-of-plane direction in insulating dielectric layers, the out-of-plane thermal conductivity of polymer films adhering to these components is particularly important. Although the thermal conductivity of polymer films is significantly lower than that of metallic and inorganic materials, an effective way to enhance the thermal conductivity of polymeric films is by generating a highly ordered structure such as crystalline or liquid-crystalline-like phases. Controlling the orientation of liquid crystalline polymers (LCPs) using a magnetic field has been reported to effectively enhance the thermal conductivity [1]. However, a strong external field must be applied to the LCP films for a long time to align the polymer chains.

Incorporating inorganic particles (fillers) with high thermal conductivity into a polymer matrix is another way to enhance the thermal conductivity of polymers. In general, when these inorganic fillers are homogeneously dispersed in a polymer matrix, the thermal conductivity of the composite is scarcely enhanced, due to the imperfect formation of percolation pathways due to insufficient contact between the fillers. Thus, using non-spherical, anisotropically shaped inorganic fillers is a judicious way to enhance the thermal conductivity of composite films. Compared with spherical fillers, anisotropic fillers have a higher probability of making contact with each other due to their 
high aspect ratios [2]. In a previous report, we demonstrated that the degree of orientation of anisotropic, platelet-shaped fillers in a composite film is nearly proportional to the anisotropy of thermal conductivity of composite films [2], controlling the orientation of anisotropic fillers is key to enhancing the out-of-plane thermal conductivity. Recently, we succeeded in preparing novel composite polyimide (PI) films containing anisotropic fillers [3]. As shown in Figure 1, a blend film was prepared by mixing poly(amic acid)s (PAAs) of BPDA-TFDB (TF) and BPDA-SDA (SD) with needle-shaped $\mathrm{ZnO}(\mathrm{n}-\mathrm{ZnO})$ particles, followed by thermal curing at $350^{\circ} \mathrm{C}$ for $1.5 \mathrm{~h}$ under a nitrogen atmosphere. A phase-separated structure spontaneously formed in the blend composite films, due to the poor miscibility between the fluorine-containing PAA and the sulfur-containing PAA. In addition, the two phases of PAAs were separately aligned along the out-of-plane direction during drying and thermal curing, which was designated a vertical double percolation (VDP) structure $[4,5]$. Since more n-ZnO particles were selectively incorporated into the TF phase (matrix phase) of the blend composite film, the orientation of the fillers was randomized by the confinement effect, and the nearly isotropic orientation of the $\mathrm{n}-\mathrm{ZnO}$ particles significantly enhanced the thermal conductivity in the blend composite films. Hence, our previous study revealed that generating a phase-separated structure effectively increases the out-of-plane thermal conductivity of the composite materials.

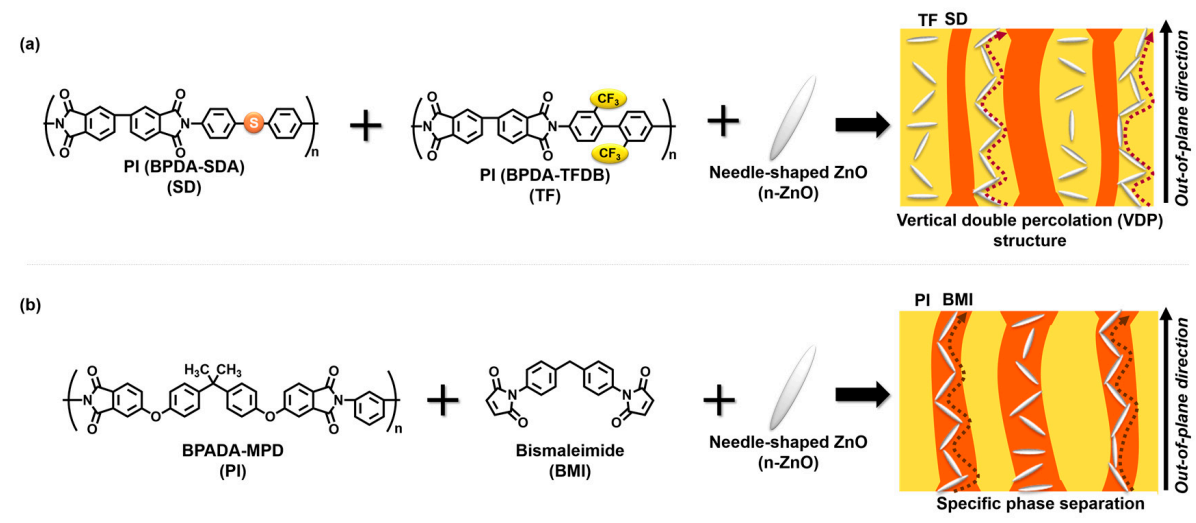

Figure 1. Specific morphology formed from phase separation of an immiscible (a) PI blend; and a (b) BMI/BPADA-MPD blend with needle-shaped $\mathrm{ZnO}(\mathrm{n}-\mathrm{ZnO})$ particles. The red/brown arrows and the white ellipsoids represent directions of thermal conduction and $\mathrm{n}-\mathrm{ZnO}$ particles, respectively.

On the other hand, a characteristics phase separation morphology was reported for a blend material derived from a soluble BPADA-MPD PI and a cross-linkable bismaleimide (BMI) resin [6,7]. According to the reference [7], the sizes of the island and sea phases could be controlled by adjusting the ratio of the amounts of components. Using this blend system, the fillers could be further confined, and the anisotropic fillers could be partly aligned along the out-of-plane direction of the composite films. In this study, we attempted to prepare new types of polymer blend composite films composed of a soluble PI (BPADA-MPD), BMI, and n-ZnO particles (Figure 1). Moreover, the relationship between the out-of-plane thermal diffusivity of the composite films and their phase-separated morphology was investigated using analytical methods such as scanning electron microscopy (SEM) and wide-angle X-ray diffraction (WAXD).

\section{Experimental Section}

\subsection{Materials}

4,4'-(4,4'-Isopropylidenediphenoxy)bis(phthalic anhydride) (BPADA), kindly supplied by Manac Co. Ltd. (Hiroshima, Japan), was used as received. 4,4'-Methylenedianiline (MPD) and 4, $4^{\prime}$-thiodianiline (SDA) were purchased from Wako Co. Ltd. (Tokyo, Japan) and sublimated under reduced pressure before use. Bismaleimide (BMI) was purchased from Tokyo Chemical 
Industry Co. Ltd. (Tokyo, Japan), N,N-dimethylacetamide (DMAc, anhydrous) was purchased from Sigma-Aldrich (St. Louis, MO, USA), and both were used as received. Needle-shaped zinc oxide $(\mathrm{n}-\mathrm{ZnO})$ particles were synthesized according to the literature [8], and the experimental details and the properties of the particles have been reported elsewhere [3]. FE-SEM micrographs of aggregated and individual $\mathrm{n}-\mathrm{ZnO}$ particles are shown in Figure S1 (Supporting Information). The length and diameter of the needle-shaped crystallites were 2-5 $\mu \mathrm{m}$ and 100-300 nm, respectively. In addition, the monodispersity of $\mathrm{n}-\mathrm{ZnO}$ particles after dispersion treatment by an ultrasonic homogenizer was monitored by particle size analyser (PSA). The PSA profiles before and after the treatment are shown in Figure S2. The monomodal dispersion observed after treatment is attributable to the size distribution of mono-dispersed $\mathrm{n}-\mathrm{ZnO}$ particles $(0.3-7 \mu \mathrm{m})$. The zeta potential of $\mathrm{n}-\mathrm{ZnO}$ particles dispersed in ethanol was estimated as $26.3 \pm 3 \mathrm{mV}$, which agrees well with the reference values of $\mathrm{ZnO}$ particles (24.0, 26.3 and $26.8 \mathrm{mV}$ at $\mathrm{pH} 7$ ) [9,10]. This positive and large zeta potential could facilitate homogenous dispersion of $\mathrm{n}-\mathrm{ZnO}$ particles in polyimide and cured $\mathrm{BMI}$ matrices.

BMI resin films containing $0-25 \mathrm{vol} \%$ of $\mathrm{n}-\mathrm{ZnO}$ particles were prepared according to the following procedure. Firstly, n-ZnO particles were dispersed in DMAc using a planetary centrifugal mixer (Thinky ARE-310, Thinky Co., Tokyo, Japan), and BMI was added to the dispersion. Then, the solution was casted onto a glass substrate and thermally cured at 155 and $250{ }^{\circ} \mathrm{C}$ for $1 \mathrm{~h}$ each under a nitrogen atmosphere.

Two kinds of PAA solutions were prepared by mixing (a) equimolar amounts of BPADA and MPD; and (b) BPADA, MPD and SDA at a molar ratio of 50:37.5:12.5 in NMP followed by stirring for one day. The solid contents of BPADA-MPD and BPADA-MPD/BPADA-SDA were preset to 15 and $17 \mathrm{wt} \%$, respectively. The PAA solutions containing $0-26 \mathrm{vol} \%$ of $\mathrm{n}-\mathrm{ZnO}$ particles were prepared according to literature $[3,5]$. The PAA solutions were casted onto glass substrates and thermally cured at $250^{\circ} \mathrm{C}$ for $1 \mathrm{~h}$.

An organic-solvent-soluble PI solution containing $\mathrm{n}-\mathrm{ZnO}$ was prepared by stirring the mixed solution of $\mathrm{n}-\mathrm{ZnO}$ particles dispersed in NMP and PI (BPADA-MPD) film dissolved in DMAc or NMP for $18 \mathrm{~h}$. To prepare the mixture solution of BPADA-MPD and BMI, BMI was added to the BPADA-MPD solution and stirred for $4 \mathrm{~h}$, in which the weight ratios of BPADA-MPD and BMI were set to 25:75. The solutions were spin-coated onto the glass substrate and thermally cured by the same procedure as BMI. The film thickness was controlled to ca. $40-45 \mu \mathrm{m}$.

\subsection{Measurements}

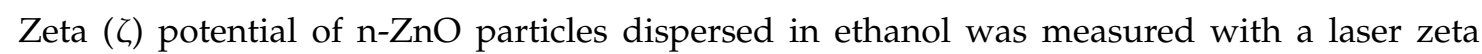
potentiometer ELS-8000 (Otsuka Electronics Co., Osaka, Japan). The value was obtained with the Smoluchowski equation by using the electrophoretic mobility, which was corrected for the electro-osmosis effect. Each measurement was repeated 5 times at a scattering angle a $20^{\circ}$. Surface images of BMI/PI/n-ZnO composite films were taken with an Olympus SZX12 microscope (Olympus Co., Tokyo, Japan). Cross-sectional images of the films were observed by desktop SEM (TM3000, Hitachi, Tokyo, Japan) using the backscattering electron method. WAXD patterns were obtained using a Bruker D8 DISCOVER (Bruker, Billerica, MA, USA) with $\mathrm{Cu}-\mathrm{K}_{\alpha}$ radiation $(50 \mathrm{kV}, 100 \mathrm{~mA})$ equipped with a Vantec 500 detector. The detector was aimed such that the normal to the detector plane was tilted by $40^{\circ}$ from the $\mathrm{X}$-ray irradiation direction to detect the diffraction from $\mathrm{n}$ - $\mathrm{ZnO}$ in the wide-angle region. Fourier transform infrared (FT-IR) spectra were recorded with a Nicolet Avatar FT-IR 320 spectroscopy (Thermo Fisher Scientific, Waltham, MA, USA) using the attenuated total reflection (ATR) method or the KBr method. The thermal expansion behaviors of PI films (BPADA-MPD, BPADA-SDA, and copolymers) were evaluated by Shimadzu TMA-60 (Shimadzu, Kyoto, Japan) with a fixed load of $1.5 \mathrm{~g}$ and a heating rate of $10^{\circ} \mathrm{C} / \mathrm{min}$. Differential scanning calorimetry (DSC, Shimadzu DSC-60, Shimadzu, Kyoto, Japan) was used to monitor the cross-linking reaction of BMI. The temperature was raised from room temperature to $300^{\circ} \mathrm{C}$ at a heating rate of $10^{\circ} \mathrm{C} / \mathrm{min}$. The thermal diffusivities along the out-of-plane direction $(D \perp)$ of PI and BMI/PI composite films were measured at room 
temperature using an AC temperature wave analyzer (ai-Phase mobile 1u, ai-phase Co. Ltd., Tokyo, Japan) [11,12]. Each film was measured ten times at different locations, and the average value was adopted as the experimental value. An elemental analysis of the composite films was performed by wavelength-dispersive spectroscopy (WDS) equipped with field-emission SEM (FE-SEM, JXA-8200, JEOL, Akishima, Tokyo, Japan). Image J software developed by the National Institutes of Health was used to analyze the area fraction of each phase of the composites, wherein the Tsai method [13] was adopted for setting the thresholds for binarization.

\section{Results and Discussion}

\subsection{Characterization of BMI and BPADA-MPD}

The polyimide (PI) and BMI/PI blend composite films were characterized using DSC, attenuated total reflection (ATR)-FT-IR, and a thermal mechanical analysis (TMA). BMI has been reported to exhibit an exothermic peak at $207^{\circ} \mathrm{C}$ in DSC, which was attributed to its cross-linking reactions [14]. The DSC curves of the BMI monomer and a BMI resin thermally cured at $250{ }^{\circ} \mathrm{C}$ for $1 \mathrm{~h}$ are presented in Figure S3. The endothermic peak appearing at $162^{\circ} \mathrm{C}$ and the broad exotherm starting around $165^{\circ} \mathrm{C}$ and peaking around $207^{\circ} \mathrm{C}$ are assignable to the melting of BMI crystallites and the cross-linking reactions, respectively. In contrast, these peaks do not appear for the cured BMI resin. Similarly, in the FT-IR spectra, the stretching vibration band attributable to the $=\mathrm{C}-\mathrm{H}$ double bond in the monomer at $3100 \mathrm{~cm}^{-1}$ disappeared with the progress of cross-linking [14]. The FT-IR spectra of both the BMI monomer and resin (Figure 2a,b) clearly exhibit the $C=O$ asymmetric stretching band $\left(1720 \mathrm{~cm}^{-1}\right)$ and $\mathrm{C}-\mathrm{N}$ stretching band $\left(1380 \mathrm{~cm}^{-1}\right)$ derived from the imide ring and $\mathrm{C}=\mathrm{C}$ stretching band $\left(1490 \mathrm{~cm}^{-1}\right)$ from the benzene rings. Meanwhile, the $=\mathrm{C}-\mathrm{H}$ stretching band of the maleimide structure $\left(3100 \mathrm{~cm}^{-1}\right)$ was only observed for the BMI monomer, indicating that the cross-linking was completed by curing at $250^{\circ} \mathrm{C}$ for $1 \mathrm{~h}$. In addition, the BMI/PI blend cured at $250{ }^{\circ} \mathrm{C}$ was characterized by FT-IR (Figure 2c). Since the $=\mathrm{C}-\mathrm{H}$ stretching vibration band of maleimide was not observed, and the $\mathrm{C}-\mathrm{N}$ stretching and $\mathrm{C}=\mathrm{O}$ symmetric and asymmetric vibrations bands of imide structure were confirmed, the cross-linking reaction of BMI and the thermal imidization of BPADA-MPD were completed after curing at $250{ }^{\circ} \mathrm{C}$.

The ATR-FT-IR spectra for the three kinds of PIs (BPADA-MPD, BPADA-SDA/MPD, and BPADA-SDA) cured at $250{ }^{\circ} \mathrm{C}$ are presented in Figure 3. All spectra clearly demonstrated the $\mathrm{C}=\mathrm{O}$ asymmetric $\left(1780 \mathrm{~cm}^{-1}\right)$ and $\mathrm{C}=\mathrm{O}$ symmetric $\left(1720 \mathrm{~cm}^{-1}\right)$ stretching bands assignable to the imide ring and the $\mathrm{C}-\mathrm{N}\left(1380 \mathrm{~cm}^{-1}\right)$ stretching band assignable to the imide-phenyl linkage. The TMA curves of the PI films are summarized in Figure S4 and Table S1. The glass transition temperature $\left(T_{\mathrm{g}}: 229^{\circ} \mathrm{C}\right.$ ) and the coefficient of thermal expansion (CTE: 47-56 ppm/K), which were estimated by TMA for BPADA-MPD, are in good agreement with the results of a previous study [15]. The PI films of BPADA-SDA and BPADA-MPD/SDA showed relatively lower $T_{\mathrm{g}}$ values $\left(220\right.$ and $\left.200{ }^{\circ} \mathrm{C}\right)$ because of their flexible thioether linkages in the main chains. The $T_{\mathrm{g}}$ values of all PIs are lower than $250{ }^{\circ} \mathrm{C}$, and thus, the thermal imidization should be completed after curing at $250{ }^{\circ} \mathrm{C}$ for $1 \mathrm{~h}$.
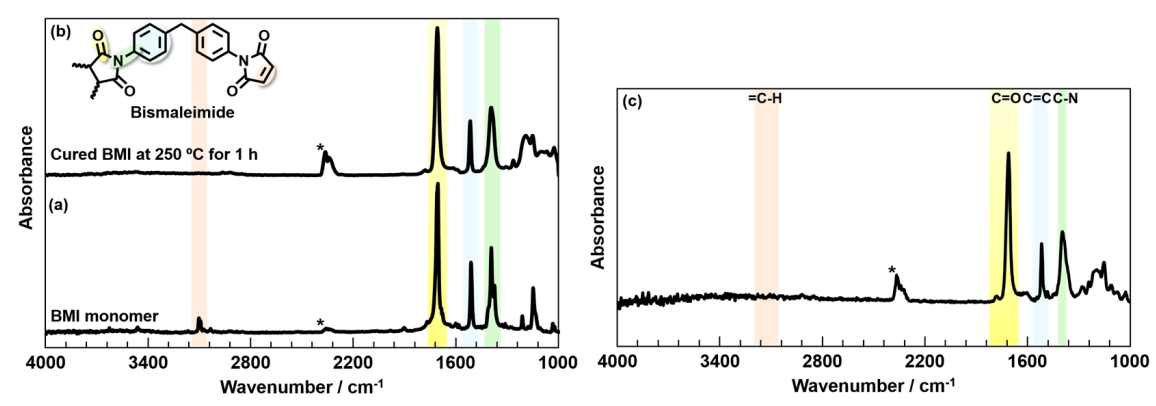

Figure 2. ATR-FT-IR spectra of (a) BMI monomer; (b) cured BMI resin; and (c) BMI/BPADA-MPD blend films. The BMI resin and BMI/PI blend film were cured at $250{ }^{\circ} \mathrm{C}$ for $1 \mathrm{~h}$. 


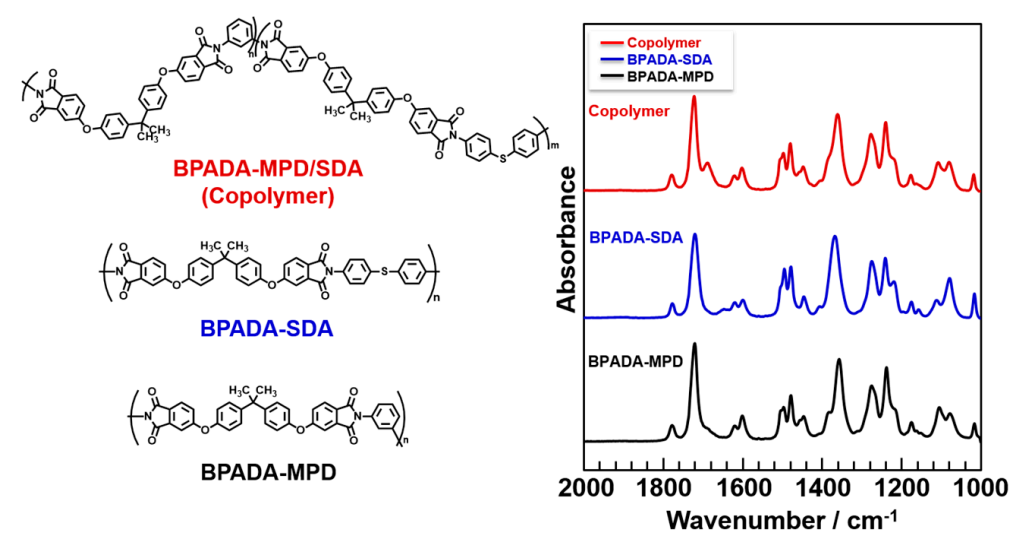

Figure 3. Structures and ATR-FT-IR spectra of PI (BPADA-SDA/MPD, BPADA-SDA, and BPADA-MPD) films.

\subsection{Characterization and Morphology of BMI/PI Composite Films}

BMI/BPADA-MPD composite films were prepared by thermally curing precursor solutions containing $\mathrm{n}-\mathrm{ZnO}$ particles at $155^{\circ} \mathrm{C}$ and $250{ }^{\circ} \mathrm{C}$ for $1 \mathrm{~h}$ each. Figure 4 presents photographs of the surface of a composite film containing $7 \mathrm{vol} \%$ of $\mathrm{n}-\mathrm{ZnO}$ captured by an optical microscope and a cross-sectional SEM image. Dark and bright regions are clearly separated in the surface image, which indicates that distinct phase separation occurred in the blend film, wherein the introduced $\mathrm{n}-\mathrm{ZnO}$ particles were preferentially incorporated into one of these phases. The SEM image also shows bright and dark regions representing the phase-separated structure, which are aligned along the out-of-plane direction. Therefore, the surface images and SEM micrographs clearly confirmed that the VDP structure $[4,5]$ was successfully formed in the blend composite film.

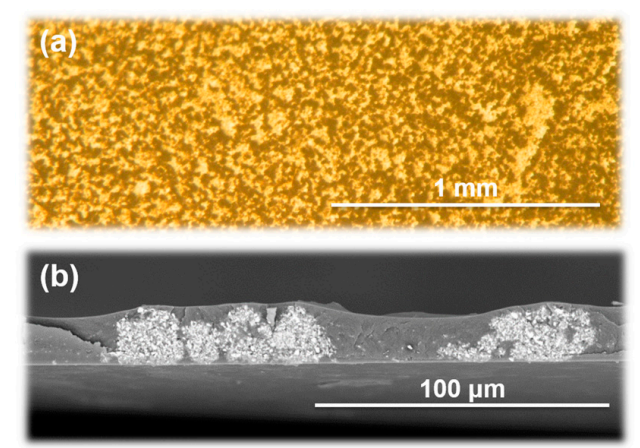

Figure 4. (a) Optical microscopic photographs; and (b) cross-sectional SEM image of BMI/BPADAMPD blend films containing $\mathrm{n}-\mathrm{ZnO}$ particles (7 vol \%).

In order to characterize the components of the island and sea phases in the BMI/PI blend composite films, an elemental analysis was performed by SEM-WDS. Since no heavy atoms are contained in the both matrices, BPADA-MPD was slightly modified by copolymerization with a sulfur-containing SDA diamine (MPD: SDA $=75: 25 \mathrm{~mol} \%$ ). The cross-sectional SEM image shown in Figure 5 demonstrates that two phases are separately aligned along the out-of-plane direction, wherein the phase separation was driven by the segregation of BPADA-MPD and cured BMI. The results of the WDS analysis for the phases with and without $\mathrm{n}-\mathrm{ZnO}$ particles are listed in Table 1 . The $\mathrm{ZnO}$-rich and $\mathrm{ZnO}$-poor phases in Figure 5 correspond to Region 1 and Region 2, respectively. Clearly, the sulfur content in Region 2 is significantly higher than that of Region 1. This difference indicates that the $\mathrm{ZnO}$-poor phase was mainly composed of the copolyimide-containing SDA, which confirms that the $\mathrm{ZnO}$-rich and $\mathrm{ZnO}$-poor phases correspond to the BMI-rich and PI-rich phases, respectively. 
Table 1. Elemental compositions analyzed by WDS in Regions 1 and 2 in Figure 5.

\begin{tabular}{ccccc}
\hline Region & Carbon (\%) & Oxygen (\%) & Sulfur (\%) & Zinc (\%) \\
\hline 1 & 58.85 & 13.29 & 0.09 & 4.01 \\
2 & 61.25 & 13.84 & 0.53 & 0.33 \\
\hline
\end{tabular}

The higher affinity of the $\mathrm{n}-\mathrm{ZnO}$ particles to $\mathrm{BMI}$ than to PIs can be supported by estimating the interfacial energies of the components as follows. The wetting coefficient $\omega$ is useful for estimating the affinity between zinc oxide and each polymer phase, and it is calculated by the following equation [16].

$$
\omega=\frac{\Gamma_{\mathrm{PI}-\mathrm{ZnO}}-\Gamma_{\mathrm{BMI}-\mathrm{ZnO}}}{\Gamma_{\mathrm{PI}-\mathrm{BMI}}}
$$

where $\Gamma_{\mathrm{PI}-\mathrm{BMI}}$ is the interfacial energy between BPADA-MPD and BMI, and $\Gamma_{\mathrm{PI}-\mathrm{ZnO}}$ and $\Gamma_{\mathrm{BMI}-\mathrm{ZnO}}$ are those between $\mathrm{ZnO}$ particles and each polymer. When $\omega>1, \mathrm{ZnO}$ particles will be preferentially incorporated into the BMI-rich phase, while in the case of $\omega<-1$, $\mathrm{ZnO}$ particles will be mainly located in the BPADA-MPD-rich phase. On the other hand, when $-1<\omega<1$, ZnO particles could be located at the interface between the BPADA-MPD-rich and BMI-rich phases. The interfacial energy $\Gamma_{1-2}$ between two components (1 and 2 ) is calculated as follows [17,18].

$$
\Gamma_{1-2}=\Gamma_{1}+\Gamma_{2}-2\left(\sqrt{\Gamma_{1}^{\mathrm{d}} \Gamma_{2}^{\mathrm{d}}}+\sqrt{\Gamma_{1}^{\mathrm{p}} \Gamma_{2}^{\mathrm{p}}}\right)
$$

where $\Gamma_{1}$ and $\Gamma_{2}$ are the surface energies of the respective components, and the superscripts $d$ and $p$ denote the dispersive and the polar components of the surface energy, respectively. The surface energies of the three components are listed in Table 2 [19-21]. Consequently, the wetting coefficient of the polymer blend system containing $\mathrm{n}-\mathrm{ZnO}$ particles is estimated to be 3.59 , which predicts that $\mathrm{n}-\mathrm{ZnO}$ particles will be preferentially incorporated into the BMI-rich phase. This analysis is obviously in good agreement with the SEM-WDS results.

\begin{tabular}{|c|c|c|c|}
\hline Materials & $\begin{array}{l}\text { Surface Energy } \\
\left(\left(\mathrm{mJ} / \mathrm{m}^{2}\right)\right.\end{array}$ & $\begin{array}{c}\text { Dispersive } \\
\text { Component }\left(\mathrm{m} / \mathrm{m}^{2}\right)\end{array}$ & $\begin{array}{l}\text { Polar Component } \\
\left(\mathrm{mJ} / \mathrm{m}^{2}\right)\end{array}$ \\
\hline BPADA-MPD & 35.1 & 32.9 & 2.2 \\
\hline BMI & 31.3 & 25.0 & 6.3 \\
\hline $\mathrm{ZnO}$ powder & 40.5 & 22.0 & 18.5 \\
\hline
\end{tabular}

Table 2. Surface energies of BPADA-MPD, BMI resin, and ZnO powder [19-21].

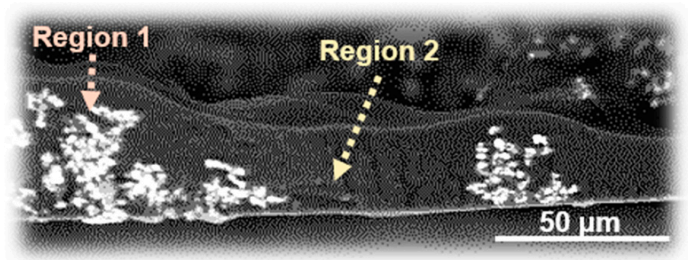

Figure 5. Cross-sectional SEM image of the BMI/copolyimide blend films containing n-ZnO particles (5 vol \%).

\subsection{Out-of-Plane Thermal Diffusivities}

The out-of-plane thermal diffusivity $(D \perp)$ of the PI, BMI, and BMI/PI blend composite films evaluated by TWA at room temperature are summarized in Figure 6 and Table S2. For comparison, the $D \perp$ values of the previously reported PI blend composite films (TF/SD) and homopolyimide (TF) films containing n-ZnO particles are also presented [3]. Firstly, the $D \perp$ values of BMI composite 
films (orange diamonds) are slightly higher than those of BPDA-TFDB (TF) composite films (green triangles). This could be due to three-dimensional cross-linking structures and the absence of the in-plane orientation of the cured BMI matrix. In the BMI composite film, no self-standing blend films were obtained for $\mathrm{n}-\mathrm{ZnO}$ contents higher than $30 \mathrm{vol} \%$ due to the high rigidity and brittleness of the films. Secondly, in the case of BPADA-MPD composite films, the $D \perp$ values (brown triangles) are slightly lower than those of the TF composite films at lower loadings ( $<15 \mathrm{vol} \%)$. The inherent $D \perp$ value of pristine BPADA-MPD film is lower than that of pristine TF film because of the flexible ether and bent $m$-phenylene linkages in its main chain, which coincides well with the analysis proposed in our previous study [22]. In contrast, the $D \perp$ of the TF composite film was lower than that of BPADA-MPD composite film in the higher loading region. We previously reported that when PIs that prefer isotropic orientation are used as matrices, the orientation of the anisotropic fillers became more isotropic in the composite films $[23,24]$. Since the BPADA-MPD chains are more randomly oriented than that of TF, $\mathrm{n}-\mathrm{ZnO}$ particles were more isotropically oriented in the BPADA-MPD composite films. Finally, TF/SD blend composite films showed significantly larger $D \perp$ values than those of homopolymer composite films, PI and TF, owing to the enhanced confinement effect and isotropic orientation of $\mathrm{n}-\mathrm{ZnO}$.

On the other hand, the BMI/PI blend films containing $\mathrm{n}-\mathrm{ZnO}$ particles presented significantly larger $D \perp$ values than all the other composite films containing immiscible PI blend films composed of $\mathrm{TF}$ and SD PIs. We recently reported that $\mathrm{n}-\mathrm{ZnO}$ particles incorporated into PI blend films are more randomly oriented than those in pristine PI films, and the percolation threshold was significantly lowered by the reduced in-plane orientation of anisotropic fillers [3]. The above result strongly suggests that $\mathrm{n}-\mathrm{ZnO}$ particles are more isotropically oriented in the BMI/BPADA-MPD blend films.

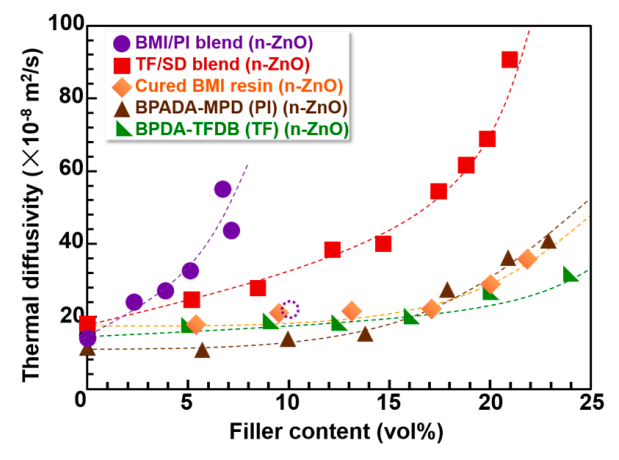

Figure 6. Filler-content dependence of the out-of-plane thermal diffusivities $(D \perp)$ for various PI, PI blend, and BMI/PI blend composite films. The significantly reduced $D \perp$ value observed for the BMI/PI blend film with a filler content of $10 \mathrm{vol} \%$ is denoted by a dotted circle.

\subsection{Image Analysis of Optical Microscope Photographs}

To estimate the area fractions of ZnO-rich phase in the BMI/PI and TF/SD blend composite films, a built-in function of the Image J software was used to analyze optical microscope images of these films, such as Figure $4 a$ in the present study and Figure $3 c$ in ref. [3]. To quantitatively estimate the surface area fraction of $\mathrm{ZnO}$-rich phase, the "area fraction" function was applied to the images after the binarization of each pixel. Then, the percentage of black pixels relative to the total number of pixels was defined as the fraction of the area containing $\mathrm{n}-\mathrm{ZnO}$ particles. As summarized in Figure 7, the area fraction containing $\mathrm{n}-\mathrm{ZnO}$ particles in the VDP structures of TF/SD blend films was proportional to the filler content, suggesting that the fraction of the volume containing n- $\mathrm{ZnO}$ particles increases with the filler content. In contrast, the area fraction of $\mathrm{n}-\mathrm{ZnO}$ rich phase in the BMI/PI composite films at small loadings $(<7 \mathrm{vol} \%)$ is remarkably lower, which indicates that the fillers are well confined in the phase-separated BMI phase of the VDP structure, as shown in Figure 4b. However, the fraction steeply increased with an increase in the filler content. In the BMI/PI composite films containing $10 \mathrm{vol} \% \mathrm{n}-\mathrm{ZnO}$, the fillers are nearly homogeneously dispersed, as shown in Figure S5, and the VDP 
structure completely collapsed. In the blend composite system, the viscosities of polymer matrix solutions should be carefully adjusted because the solution viscosity significantly increased with the increasing filler content. In the case of the TF/SD blend solution [3,5], the viscosity of each PI solution with or without fillers could be separately adjusted. However, the viscosity of BMI monomer solutions containing fillers was hardly adjusted in this study. Therefore, the solution viscosity of the blend system simultaneously increased with the increasing filler content. This could explain the drastic change in the morphology, that is, the collapse of VDP structure, in the BMI/PI composite films with the higher filler contents. This morphological change caused a steep decrease in $D \perp$ from $54.1 \times 10^{-8} \mathrm{~m}^{2} / \mathrm{s}$ (filler content: $7 \mathrm{vol} \%$ ) to $20.5 \times 10^{-8} \mathrm{~m}^{2} / \mathrm{s}(10 \mathrm{vol} \%)$ in Figure 6 , which also demonstrates that the VDP structure is a very effective way to form thermally conductive pathways along the out-of-plane direction.

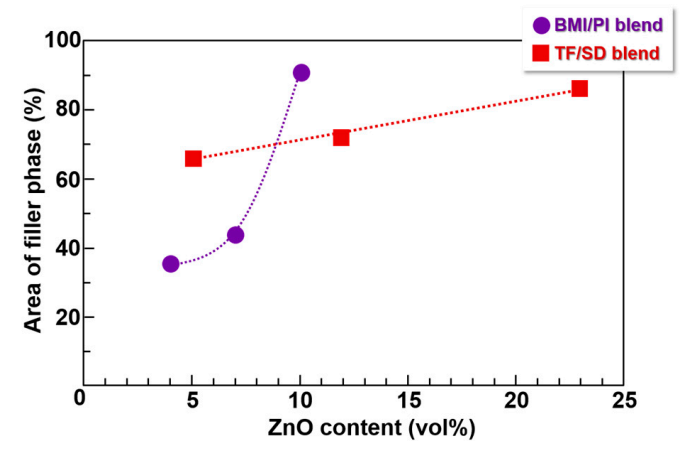

Figure 7. Variation in the area containing $\mathrm{n}-\mathrm{ZnO}$ particles with the $\mathrm{ZnO}$ content for BMI/PI and TF/SD blend films.

\subsection{Orientation Analysis of Composite Films by WAXD}

As mentioned in the Introduction, controlling the orientation of anisotropic fillers and the phase-separation morphology are crucial to enhancing the out-of-plane thermal conductivity in composite films. To examine the orientations of the $\mathrm{n}-\mathrm{ZnO}$ particles in the composite films, wide-angle $\mathrm{X}$-ray diffraction (WAXD) measurements were performed. Since the diffraction patterns of $\mathrm{n}$ - $\mathrm{ZnO}$ are observed in the wide-angle region beyond $2 \theta=30^{\circ}$ [25], thereby exceeding the CCD detection area of the diffractometer, the normal to the detector plane was tilted $40^{\circ}$ from the direction of the $\mathrm{X}$-ray radiation to detect very wide-angle diffraction [3]. The WAXD patterns of $\mathrm{n}-\mathrm{ZnO}$ particles incorporated into the composite films are shown in Figure 8. The diffractions of the (100) and (002) planes for $\mathrm{n}-\mathrm{ZnO}$ were observed in the patterns [26]. Hence, the orientation of the dispersed $\mathrm{n}-\mathrm{ZnO}$ particles in the matrix can be analyzed by the azimuthal intensity distribution of the (100) direction. Figure 9 presents the variations in the full-width at half-maximum, $\Delta \beta$, of the intensity distribution in the azimuthal direction for the (100) diffractions of $\mathrm{n}-\mathrm{ZnO}$. When the $\mathrm{n}-\mathrm{ZnO}$ particles are oriented in the in-plane direction, the distribution of the (100) diffraction intensity as a function of $\beta$ leads to a small $\Delta \beta$. In contrast, when the fillers are more randomly oriented, the (100) diffraction intensity distribution becomes quite broad, with a large $\Delta \beta$. The $\Delta \beta$ values of $\mathrm{n}-\mathrm{ZnO}$ particles observed for the TF/SD PI blend composite films are also plotted for comparison [3]. Notably, the $\Delta \beta$ values of the BMI and BPADA-MPD composite films are significantly higher than those of TF/SD blend composite films at lower filler loadings $(<7 \mathrm{vol} \%)$. This indicates that the out-of-plane component of the orientation vector of $\mathrm{n}-\mathrm{ZnO}$ particles incorporated into the BMI/PI blend films is larger than those in the TF/SD films. As previously described [3], when PI blend composite films were prepared with n-ZnO particles, the in-plane orientation of $\mathrm{n}-\mathrm{ZnO}$ particles were effectively obstructed by boundaries between two phases, which induced the relatively isotropic orientation of the $\mathrm{n}-\mathrm{ZnO}$ particles. Additionally, the volume fraction of the ZnO-rich phase in the BMI/PI blend composite films was smaller than that in the TF/SD PI blend composite films at low filler loadings (Figure 7). Therefore, the $\mathrm{n}-\mathrm{ZnO}$ particles 
were more isotropically oriented in the BMI/PI composite films owing to the reduced volume fraction of the ZnO-rich phase and the boundaries between BMI and PI phases. This structural character is beneficial to preparing composite materials exhibiting higher thermal conductivity with very low filler contents and to lowering the percolation threshold of the composite materials. However, the $\Delta \beta$ values for the azimuthal intensity distribution of $\mathrm{n}-\mathrm{ZnO}$ particles in the BMI/PI, PI, and BMI composite films were gradually decreased with the increase in the filler content, except for the TF/SD composite films. The narrowing of the (100) diffraction peaks of the azimuthal intensity profile indicates that as the content of the anisotropic $\mathrm{n}-\mathrm{ZnO}$ particles increased, the particles gradually oriented to the in-plane direction in the matrices [3], which coincides with the increase in the area fraction of $\mathrm{ZnO}$-rich phase (Figure 7). In contrast, the out-of-plane orientation of the $\mathrm{n}-\mathrm{ZnO}$ particles in the TF/SD composite films gradually increased with the aid of the VDP structures [3]. These results confirm that promoting the alignment of the $\mathrm{n}-\mathrm{ZnO}$ particles along the out-of-plane direction by controlling the morphology of the phase-separated structures is a very effective way to enhance the $D \perp$ of the blend composite materials.

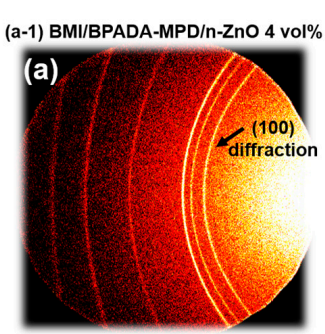

(b-1) BMI/n-Zno 5 vol\%

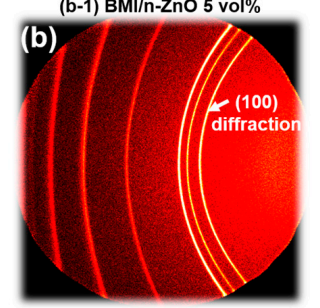

(c-1) BPADA-MPD/n-Zno 5 vol\%

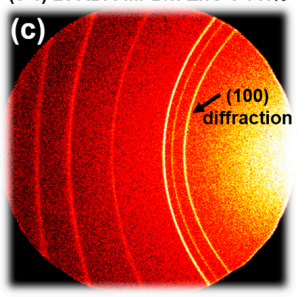

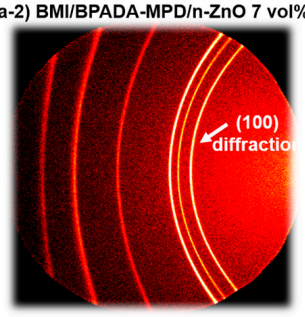

(b-2) BMI/n-ZnO 10 vol\%

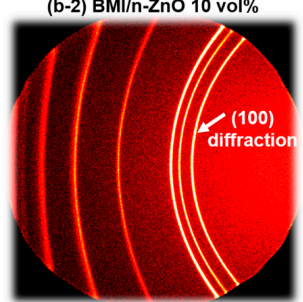

(c-2) BPADA-MPD/n-Zno 10 vol\%

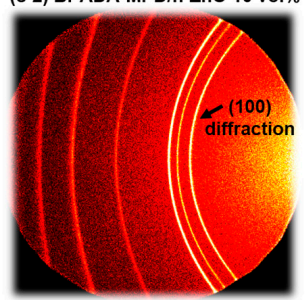

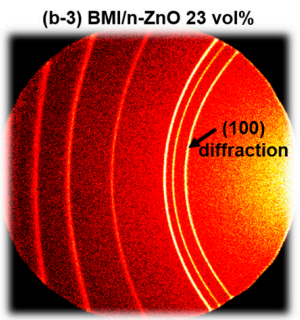

(c-3) BPADA-MPD/n-ZnO 23 vol\%

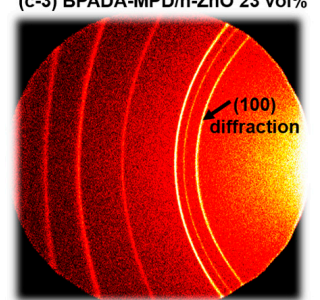

Figure 8. WAXD patterns of $\mathrm{n}-\mathrm{ZnO}$ particles incorporated into (a) BMI/BPADA-MPD/n-ZnO blend (4 and $7 \mathrm{vol} \%$ ); (b) BMI/n-ZnO (5, 10 and $23 \mathrm{vol} \%$ ); and (c) BPADA-MPD/n-ZnO (5, 10 and $23 \mathrm{vol} \%$ ) composite films.

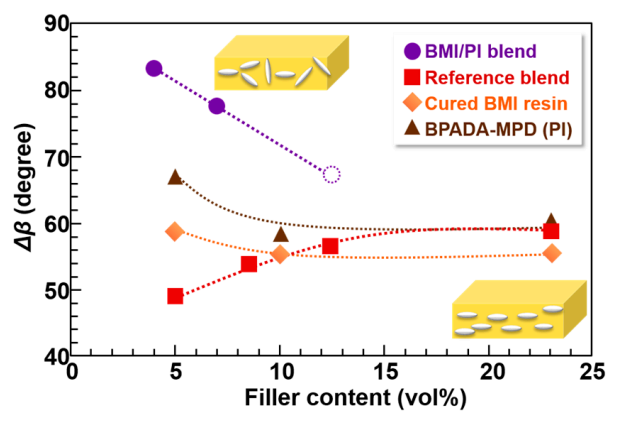

Figure 9. Full-width at half-maximum of the azimuthal intensity distribution of (100) diffraction, $\Delta \beta$, for four kinds of composite films with various $\mathrm{n}-\mathrm{ZnO}$ contents. 


\section{Conclusions}

The out-of-plane thermal diffusivity $(D \perp)$ of novel BMI/polyimide (BPADA-MPD) blend composite films containing needle-shaped $\mathrm{ZnO}$ particles was investigated based on structural and morphological analyses using ATR-FT-IR, FE-SEM with WDS, WAXD, and image analysis. The $\mathrm{ZnO}$-rich and $\mathrm{ZnO}$-poor phases were separately aligned along the out-of-plane direction in the composite films, exhibiting the VDP structure, and the anisotropic fillers were selectively incorporated into the BMI-rich phase due to the difference in wettability between the BMI and BPADA-MPD matrices. At lower filler contents ( $<7 \mathrm{vol} \%$ ), the $D \perp$ values of the novel composite films were significantly higher than those of the previously reported composite films. A surface image analysis clarified that the area fraction of the $\mathrm{ZnO}$-rich phase in the novel composite films was significantly smaller than those of the previously prepared composite films, and thus, the $\mathrm{n}-\mathrm{ZnO}$ particles were more isotropically oriented in the blend composite films. However, the $D \perp$ values significantly decreased, accompanied by a steep increase in the area fraction of the ZnO-rich phase due to the collapse of the VDP structure at higher filler contents ( $>10 \mathrm{vol} \%$ ). Consequently, the significant increase in $D \perp$ observed in the novel blend composite films could be attributed to the effective formation of thermally conductive pathways along the out-of-plane direction due to the closer confinement and the randomized orientation of the $\mathrm{n}-\mathrm{ZnO}$ particles in the composite films.

Supplementary Materials: The following are available online at www.mdpi.com/2073-4360/9/7/263/s1, Figure S1: FE-SEM image of aggregated $\mathrm{n}-\mathrm{ZnO}$ and needle-shaped $\mathrm{n}-\mathrm{ZnO}$ particles; Figure S2: Particle size dispersions of $\mathrm{n}-\mathrm{ZnO}$ (a) before and (b) after dispersion treatment measured by a particle size analyzer (Microtrac HRA9320, Honeywell International Inc., Morris Plains, NJ, USA); Figure S3: DSC thermograms of BMI monomer and BMI resin prepared by thermally curing at $250^{\circ} \mathrm{C}$ for $1 \mathrm{~h}$; Figure S4: TMA curves of PI (BPADA-SDA/MPD, BPADA-SDA, and BPADA-MPD) films; Figure S5: Cross-sectional SEM image of BMI/BPADA-MPD composite film ( $\mathrm{ZnO}$ content: $10 \mathrm{vol} \%$ ); Table S1: Thermomechanical data of PI films; Table S2: n-ZnO content $\left(\phi_{\mathrm{p}}\right)$ and thermal diffusivity $D \perp$ of PI (BPADA-MPD), BMI, and BMI/PI blend composite films. These data are plotted in Figure 6.

Acknowledgments: The authors thank Masatoshi Tokita, Mitsuru Satoh, and Toshihiro Isobe at Tokyo Institute of Technology for utilization of wide angle X-ray diffraction instrument, zeta potential analyzer, and particle size analyzer, respectively. The authors also thank Jun Koki and Masaru Tada of the division of materials analysis, Tokyo Institute of Technology for support of SEM-WDS analysis. The synchrotron radiation experiments were performed at BL-10C of High Energy Accelerator Research Organization with the approval of the Photon Factory Program Advisory Committee (Proposal No. 2014G708 and 2016G544). This work was partially supported by Grants-in-Aid for Scientific Research (25288096, 15K13782, 16F16046), Japan Society for the Promotion of Science.

Author Contributions: Shinji Ando and Shoya Uchida planned this project. Shoya Uchida conducted the experiments, and Shinji Ando directed the project. Shoya Uchida, Ryohei Ishige and Shinji Ando analyzed data and co-wrote the paper.

Conflicts of Interest: The authors declare no conflict of interest.

\section{References}

1. Shen, H.; Cai, C.; Guo, J.; Qian, Z.; Zhao, N.; Xu, J. Fabrication of oriented hBN scaffolds for thermal interface materials. RSC Adv. 2016, 6, 16489-16494. [CrossRef]

2. Tanimoto, M.; Yamagata, T.; Miyata, K.; Ando, S. Anisotropic thermal diffusivity of hexagonal boron nitride-filled polyimide films: Effects of filler particle size, aggregation, orientation, and polymer chain rigidity. ACS Appl. Mater. Interfaces 2013, 5, 4374-4382. [CrossRef] [PubMed]

3. Uchida, S.; Murakami, T.; Iwamura, T.; Ishige, R.; Ando, S. Enhanced thermal conductivity in immiscible polyimide blend composites with needle-shaped ZnO particles. RSC Adv. 2017, 7, 15492-15499. [CrossRef]

4. Yorifuji, D.; Ando, S. Enhanced thermal diffusivity by vertical double percolation structures in polyimide blend films containing silver nanoparticles. Macromol. Chem. Phys. 2010, 211, 2118-2124. [CrossRef]

5. Yorifuji, D.; Ando, S. Enhanced thermal conductivity over percolation threshold in polyimide blend films containing $\mathrm{ZnO}$ nano-pyramidal particles: Advantage of vertical double percolation structure. J. Mater. Chem. 2011, 21, 4402-4407. [CrossRef]

6. Zhao, L.; Li, L.; Than, J.; Zhuang, J.; Li, S. Synthesis and characterization of bismaleimidepolyetherimide-titania hybrid. Compos. Part A 2004, 35, 1217-1224. [CrossRef] 
7. Jiao, Y.; Yuan, L.; Liang, G.; Gu, A. Facile preparation and origin of high-k carbon nanotube/poly(ether imide)/bismaleimide composites through controlling the location and distribution of carbon nanotubes. J. Phys. Chem. C 2014, 118, 24091-24101. [CrossRef]

8. Iwamura, T.; Goto, S.; Sakaguchi, M.; Chujo, Y. Synthesis of submicrometer zinc oxide particles and zinc oxide nanowires using microwave irradiation. Chem. Lett. 2016, 45, 508-510. [CrossRef]

9. Fiedot, M.; Maliszewska, I.; Rac, O.; Woźniak, P.S.; Teterycz, H. The relationship between the mechanism of zinc oxide crystallization and its antimicrobial properties for the surface modification of surgical meshes. Materials 2017, 10, 353. [CrossRef]

10. Kim, K.M.; Choi, M.H.; Lee, J.K.; Jeong, J.; Kim, Y.R.; Kim, M.K.; Paek, S.M.; Oh, J.M. Physicochemical properties of surface charge-modified $\mathrm{ZnO}$ nanoparticles with different particle size. Int. J. Nanomed. 2014, 9 , 41-56. [PubMed]

11. Hashimoto, T.; Morikawa, J.; Kurihara, T.; Tsuji, T. Frequency dependent thermal diffusivity of polymers by temperature wave analysis. Thermochim. Acta 1997, 304, 151-156. [CrossRef]

12. Morikawa, J.; Hashimoto, T. Thermal diffusivity of aromatic polyimide thin films by temperature wave analysis. J. Appl. Phys. 2009, 105, 113506-1-9. [CrossRef]

13. Tsai, W.H. Moment-preserving thresholding: A new approach. Comput. Vis. Graph. Image Process. 1985, 29, 377-393. [CrossRef]

14. Takeichi, T.; Saito, Y.; Agag, T.; Muto, H.; Kawauchi, T. High performance polymer alloys of polybenzoxazine and bismaleimide. Polymer 2008, 49, 1173-1179. [CrossRef]

15. Belana, J.; Cañadas, J.C.; Diego, J.A.; Mudarra, M.; Diaz, R.; Friederichs, S.; Jaims, C.; Sanchis, M. Physical ageing studies in polyetherimide ULTEM 1000. Polym. Int. 1998, 46, 29-32. [CrossRef]

16. Sumita, M.; Sakata, K.; Asai, S.; Miyasaka, K.; Nakagawa, H. Dispersion of fillers and the electrical conductivity of polymer blends filled with carbon black. Polym. Bull. 1991, 25, 265-271. [CrossRef]

17. Vandebril, S.; Vermant, J.; Moldenaers, P. Efficiently suppressing coalescence in polymer blends using nanoparticles: Role of interfacial rheology. Soft Matter 2010, 6, 3353-3362. [CrossRef]

18. Owens, D.K.; Wendt, R.C. Estimation of the surface free energy of polymers. J. Appl. Polym. Sci. 1969, 13, 1741-1747. [CrossRef]

19. Park, M.J.; Kim, D.S.; Kong, J.W.; Kim, M.; Kim, W.; Park, I.S. Interfacial adhesion and microfailure modes of electrodeposited carbon fiber/epoxy-PEI composites by microdroplet and surface wettability tests. J. Colloid Interface Sci. 2002, 249, 62-77. [CrossRef] [PubMed]

20. Chen, J.W.; Wightman, J.P. Surface characterization and adhesive bonding of toughened bismaleimide composites. Compos. Part A 1996, 27, 419-428. [CrossRef]

21. Torchnsky, I.; Rosenman, G. Wettability modification of nanomaterials by low-energy electron flux. Nanoscale Res. Lett. 2009, 4, 1209-1217. [CrossRef]

22. Yorifuji, D.; Ando, S. Molecular structure dependence of out-of-plane thermal diffusivities in polyimide films: A key parameter for estimating thermal conductivity of polymers. Macromolecules 2010, 43, 7583-7593. [CrossRef]

23. Tanimoto, M.; Ando, S. Effect of chain rigidity/flexibility of polyimides on morphological structures and thermal diffusivity of hBN-filled composites. Compos. Sci. Technol. 2014, 99, 103-108. [CrossRef]

24. Tanimoto, M.; Ando, S. Prevention of void formation in particulate-filled polymer composites: Effects of thermoplastic matrices and residual solvent. Compos. Sci. Technol. 2016, 123, 268-275. [CrossRef]

25. Smith, J.V. (Ed.) Index (Inorganic) to the Powder Diffraction File; American Society for Testing and Materials: Philadelphia, PA, USA, 1967.

26. Znaidi, J.; Illia, G.J.A.A.S.; Benyahia, S.; Sanchez, C.; Kanaev, A.V. Oriented ZnO thin films synthesis by sol-gel process for laser application. Thin Solid Films 2003, 428, 257-262. [CrossRef]

(C) 2017 by the authors. Licensee MDPI, Basel, Switzerland. This article is an open access article distributed under the terms and conditions of the Creative Commons Attribution (CC BY) license (http://creativecommons.org/licenses/by/4.0/). 